\title{
Um estudo sobre o desempenho da agroindústria canavieira no Estado de Pernambuco no período de 1987 a 1996
}

\author{
Eunice Paraguassu Moura \\ E-mail:planasp@ufpe.br \\ Maria Auxiliadora do Nascimento Mélo \\ E-mail:manmelo@ufpe.br \\ Denise Dumke de Medeiros \\ E-mail:ddm@ufpe.br
}

Grupo de Pesquisa PLANASP/Departamento de Engenharia de Produção

Universidade Federal de Pernambuco

\begin{abstract}
Resumo
Este trabalho visa avaliar o desempenho do setor agroindustrial canavieiro no Estado de Pernambuco no período entre 1987 e 1996, após a retirada dos incentivos concedidos pelo Proálcool, no qual o setor ficou mais exposto às condições de mercado. São apresentados aspectos da agroindústria açucareira, a contextualização atual do setor e conceitos importantes ligados ao tema. Em seguida, faz-se uma breve avaliação dos efeitos do Programa Proálcool na expansão do setor. É apresentado o referencial teórico adotado e realizado um estudo do desempenho competitivo. Conclui-se, com seu comportamento no período considerado, quanto a mercado, eficiência e capacitação.
\end{abstract}

Palavras-chave

Competitividade, agroindústria, Indicadores de desempenho.

\section{A study on the acting of sugar agrobusiness in the state of pernambuco in the period from 1987 to 1996}

\begin{abstract}
This work seeks to evaluate the acting of the section sugar agrobusiness in Pernambuco state during the period between 1987 and 1996, after the retreat of the incentives granted by Proálcool. Aspects of the section, the current context and important concepts linked to the theme are presented. Soon after, makes a brief evaluation of Proálcool effects in the expansion of the section. The adopted and accomplished theoretical referencial is presented a study of the competitive acting. It is concluded with its behavior in the considered period, with relationship to the market, efficiency and training.
\end{abstract}

Key words

Competitiveness, agrobusiness, performance indicators. 


\section{INTRODUĈ̣̃O}

O setor agroindustrial canavieiro é um dos mais representativos setores de produção do Brasil, não somente quando se considera o caso específico do Estado de Pernambuco, mas também a própria economia do País como um todo. O Brasil ocupa o primeiro lugar na produção mundial de cana-de-açúcar, sendo o segundo produtor de açúcar do mundo, ultrapassado apenas pela Índia. A produção do setor agroindustrial canavieiro representa aproximadamente $1,5 \%$ da produção total de bens e serviços no País. Em Pernambuco, o setor responde por uma parcela de, aproximadamente, $4 \%$ do produto total da economia do Estado.

Vale salientar, ainda, que a atividade canavieira é responsável, em toda a região da Zona da Mata pernambucana, pela quase totalidade dos postos de trabalho disponíveis. Em época de safra, a mesma chega a empregar cerca de $6 \%$ da mão-de-obra do Estado (BARROS, 1996). Assim, além de representar um dos mais importantes setores de produção do Estado, o setor canavieiro pernambucano também desempenha um instrumento fundamental para a geração de postos de trabalho.

Nesse contexto, é importante frisar que a manutenção dessa atividade, ao prover todo esse contigente de mãode-obra na região dos canaviais, diminui significativamente o êxodo rural para as grandes cidades, evitando, dessa forma, o agravamento dos problemas sociais relativos à elevada densidade demográfica dos centros urbanos (LIMA; SILVA, 1995).

Ainda com relação ao emprego da mão-de-obra estadual, existem alguns números que retratam muito bem o que representa a atividade canavieira como fonte geradora de postos de trabalho no Estado de Pernambuco. Por exemplo, os 6.937 estabelecimentos agrícolas envolvidos com a produção de cana-de-açúcar no Estado, no ano de 1996, chegaram a empregar um total de 106.349 pessoas, o que representa algo em torno de 3\% da população economicamente ativa do Estado (IBGE, 1996).

A importância desse setor também é justificada pela influência do mesmo em outros setores da economia tais como: agricultura; indústria extrativa; indústria de transformação; energia elétrica; construção civil; comércio; transporte, armazenamento e telecomunicações; atividades financeiras, imóveis e serviços às empresas; serviços comunitários, etc. segundo Jalfrim (1997). Como visto anteriormente, pelo número de pessoas que emprega, é natural que o desempenho do setor agroindustrial cana- vieiro afete diretamente uma série de outros setores, principalmente o comércio, na medida em que representa o grande gerador de renda de uma parcela significativa da força de trabalho em Pernambuco.

Acredita-se, pelo exposto acima, que ainda é considerável a influência do setor canavieiro nos principais indicadores da economia de Pernambuco. Embora a mesma já tenha sido muito mais significativa em décadas anteriores, essa atividade vem diminuindo significativamente a sua parcela de contribuição para o sistema produtivo do Estado como um todo.

Dessa forma, pela importância que exerce sobre a economia de Pernambuco, qualquer acontecimento que afete o referido setor de produção torna-se de grande relevância para o desempenho da produção global do Estado.

\section{A produção do setor agroindustrial canavieiro aproximadamente $1,5 \%$ da produção total de bens e serviços no País.}

Pode-se observar que o comportamento do setor agroindustrial canavieiro pernambucano vem se apresentando de forma instável nas últimas décadas. Acredita-se que, devido a uma série de problemas ainda não bem identificados, o setor vem passando por grandes dificuldades, resultando em um processo de fechamento de usinas e diminuição do volume de produção, o que tem provocado a perda da importância desse setor para a economia de Pernambuco, bem como para a economia nacional.

Assim, pelo que representa o setor agroindustrial canavieiro para a economia do Estado de Pernambuco, e pelas dificuldades surgidas ao longo dos últimos anos, torna-se indispensável conhecer as verdadeiras causas que motivaram o aparecimento dos empecilhos ao desempenho satisfatório do setor canavieiro pernambucano, de forma que se possa sugerir, com maior propriedade, algumas soluções que possam viabilizar a retomada do andamento normal das atividades naquele importante setor produtivo.

\section{PROBLEMÁTICA}

$\mathrm{Na}$ atividade agrícola, a produção está exposta a alguns fatores, muitas vezes, imprevisíveis e sem controle pelo homem, tais como, ocorrência de secas, proliferação de pragas, etc.

Assim, esses fenômenos são utilizados como justificativa para a existência de programas de crédito subsidiado, políticas de garantia de mercado e preços mínimos. Ou seja, tendo em vista que fenômenos da natureza 
podem surgir a qualquer momento, os produtores não podem deixar de ter algumas facilidades e garantias para que se sintam mais seguros em produzir.

Entende-se, então, que a intervenção do governo na atividade agrícola justifica-se pela existência de falhas na obtenção de informações que são importantes para as decisões de investimento (CARVALHO, 1998). Assim, a presença do governo oferecendo garantia de mercado para a produção, bem como recursos financeiros a custos mais baixos (subsídio), funciona como um incentivo, muitas vezes, indispensável para que alguns produtos originários do setor em questão possam ser produzidos na quantidade necessária para atender os desejos dos consumidores.

Nesse sentido, a existência de programas de subsídio como, por exemplo, o Programa Nacional do Álcool Proálcool pôde garantir um nível elevado de produção na atividade canavieira, já que o Estado passou a assumir a quase totalidade dos riscos envolvidos naquela atividade.

Em meio à crise do petróleo durante os anos 70, o governo brasileiro lançou, em 1975, o Programa Nacional do Álcool. O objetivo imediato desse programa era ampliar a oferta de álcool para fins carburantes, com a finalidade de reduzir as importações de petróleo, dado que seu preço havia quadruplicado no mercado internacional, passando, de mais ou menos US\$ 3,00, para algo em torno de US\$ 12,00 o barril. Portanto, a criação do programa foi justificada pelo Governo Federal pela necessidade de se buscar alternativas de substituição do petróleo, que era importado, pelo álcool produzido internamente.

Embora tenha surgido com o propósito de resolver um problema de desequilíbrio nas contas externas do País, ocasionado pela grande elevação do preço do petróleo no mercado internacional (1973/74), a verdade é que a magnitude das facilidades e subsídios envolvidos alavancou uma série de investimentos no setor da agroindústria canavieira. Esses investimentos surgiram, principalmente, a partir de 1979 e foram de grande importância, não apenas para a ampliação da capacidade produtiva, como também para a modernização daquele ramo de atividade (LOPES, 1996).

Logo em seguida, coincidindo com a retirada dos incentivos desse programa, muitas dificuldades começaram a aparecer, provocando a falência de várias unidades produtoras, principalmente no Estado de Pernambuco.

No entanto, quando tal programa é extinto e algumas unidades produtoras são mais atingidas do que outras, mostra que existem diferenças em termos de eficiência entre as mesmas. Ou seja, o Proálcool deve ter favorecido a expansão do setor agroindustrial canavieiro brasileiro, mas não significa que as unidades produtoras tornaram-se igualmente eficientes, capacitadas, etc. É muito comum que se atribua à extinção do Proálcool a respon- sabilidade pelos problemas que o setor canavieiro pernambucano vem atravessando nos últimos anos. Contudo, observando a situação no resto do País, nota-se que o referido setor expandiu-se no mesmo período, fato que coloca em dúvida essa explicação. Torna-se bastante oportuno, desse modo, analisar, com maior cuidado, a situação do setor canavieiro de Pernambuco, para que incertezas como essas possam começar a ser esclarecidas, e prováveis soluções sejam encontradas.

Desse modo, o objetivo central do trabalho de pesquisa que foi desenvolvido era avaliar o desempenho competitivo do setor agroindustrial canavieiro pernambucano, ao longo do período que vai de 1987 a 1996, período esse que coincide com o enfraquecimento e extinção do Proálcool. A importância maior desse período é que o mesmo permite que o setor seja estudado sob condições de maior exposição ao mercado, isto é, à concorrência.

A escolha do período 87/96, que coincide com o fim dos incentivos proporcionados pelo Proálcool, não tem por objetivo apontar o fim daquele programa como causador das atuais dificuldades, pois isso também deveria ser verdadeiro para o restante do País. Ao contrário, a partir de um conjunto de indicadores de desempenho, aplicados para os dados do setor de produção em estudo, o que se vai procurar testar é se o desempenho competitivo do setor foi realmente insatisfatório naquele período, o que daria às atuais dificuldades uma outra dimensão.

\section{METODOLOGIA APLICADA}

Acredita-se que todo estudo sobre competitividade envolve a seleção de indicadores, já que existe uma variedade muito grande e nem todos são aplicáveis, ou mesmo relevantes, em todos os trabalhos. Sejam eles quantitativos ou qualitativos, devem se enquadrar em três dimensões apropriadas, tais como: empresariais, setoriais e sistêmicas. Dentro de cada uma das dimensões citadas, podem ser abordados aspectos de eficiência, capacitação e desempenho (COUTINHO; FERRAZ, 1995).

Uma das principais etapas do trabalho foi a escolha de indicadores de avaliação do desempenho competitivo, que fossem mais adequados à pesquisa.

Neste trabalho, que tem como objetivo geral avaliar a representação do setor agroindustrial canavieiro de Pernambuco, no período de 1987 a 1996, a atuação competitiva foi tratada a partir da dimensão setorial, dando-se ênfase à utilização de indicadores de desempenho, eficiência e capacitação.

Tal escolha levou em consideração alguns dos indicadores que constam de uma extensa lista sugerida por Coutinho; Ferraz (1995), possibilitando, desse modo, abordar as três modalidades acima mencionadas. 
Os critérios adotados para a escolha dos indicadores utilizados nessa pesquisa levaram em conta cinco aspectos: a dimensão do desempenho competitivo (setorial), os objetivos de desempenho propostos (desempenho, eficiência e capacitação), as especificidades do setor canavieiro, os objetivos do próprio trabalho e, ainda, a disponibilidade das informações necessárias.

Assim, de acordo com os critérios estabelecidos, foram selecionados os seguintes indicadores:

- Indicadores de desempenho: taxa de crescimento das vendas externas, relação exportações/produção, exportações locais/exportações nacionais, evolução do preço de venda.

- Indicadores de eficiência: produtividade da terra, custo da mão-de-obra.

- Indicadores de capacitação: escolaridade da mão-deobra, gastos com pesquisa e desenvolvimento.

\section{RESULTADOS OBTIDOS}

Com a aplicação dos indicadores citados anteriormente, foi possível analisar a atuação do setor canavieiro pernambucano, ao longo do período analisado. Uma síntese da análise dos principais indicadores é apresentada a seguir.

\section{Indicadores de Desempenho do Setor Canavieiro}

Com relação aos indicadores de desempenho no mer- cado, o comportamento demonstrou que a performance do setor em Pernambuco foi totalmente insatisfatória, levando-se em conta todos os aspectos analisados. O setor açucareiro local perdeu posição em todos os indicadores apresentados, não conseguindo acompanhar a performance nacional do mesmo setor. Como exemplo, pode-se observar o comportamento do indicador exportações locais/exportações nacionais (Figura 1). Quando esta relação apresenta uma tendência de elevação é porque o setor local vem obtendo um desempenho mais satisfatório do que os demais Estados brasileiros.

Observando atentamente a Figura 1, pode-se ver que a relação entre as exportações locais de açúcar e as exportações nacionais declina continuamente através do período analisado, mostrando que o setor açucareiro pernambucano obteve um desempenho bastante insatisfatório. Pode-se dizer que os produtores locais não conseguiram acompanhar a performance dos produtores dos demais Estados em termos da evolução da quantidade vendida no mercado internacional.

Esse indicador, além de fornecer um indicativo da performance do Estado de Pernambuco em si, mostra também a situação em relação ao país como um todo. Ou seja, além de um indicador absoluto da situação local, o mesmo torna-se muito mais uma medida relativa da situação em andamento. A Figura 2 retrata o seu comportamento ao longo do período em estudo.

Figura 1: Exportações de açúcar - Pernambuco/Brasil (1987-95).

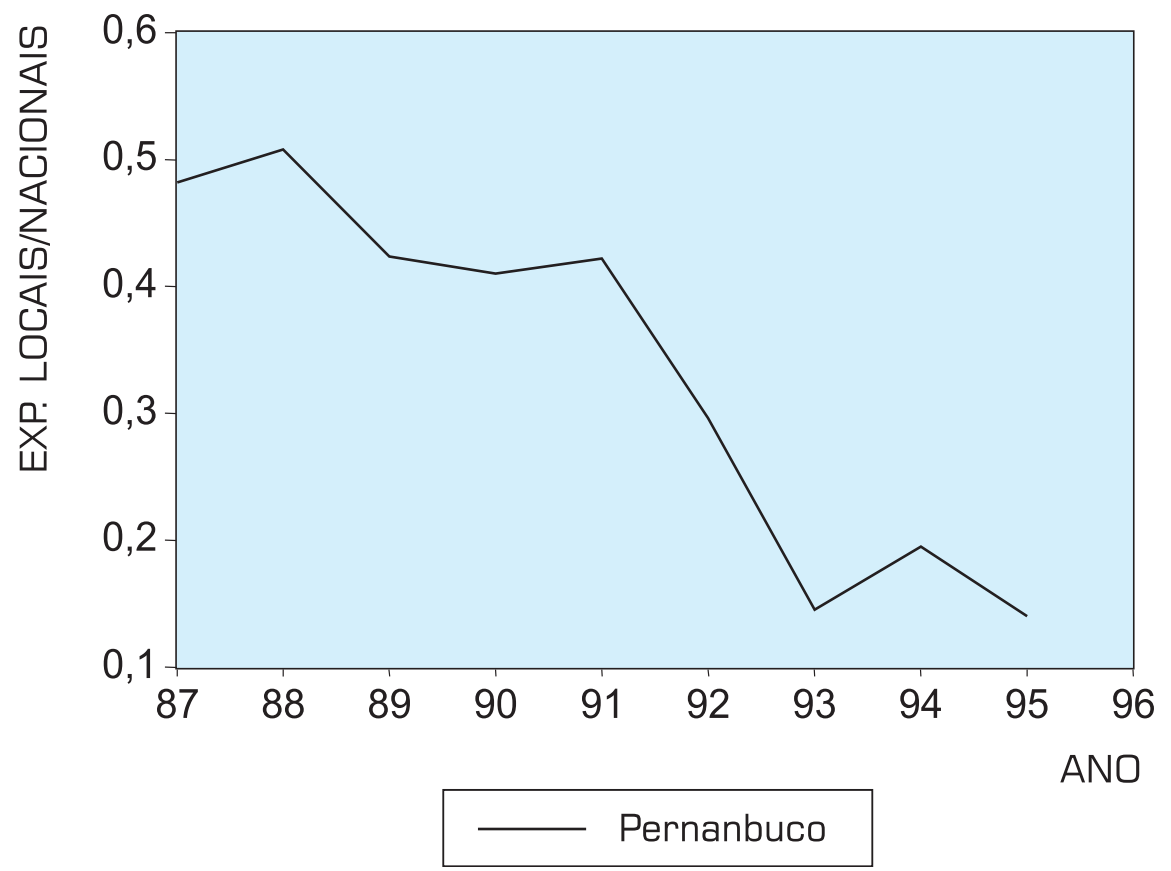

Fonte: Sindaçúcar e Banco Central. 
Como pode ser concluído a partir da Figura 1, o Estado de Pernambuco não conseguiu acompanhar a performance dos demais Estados no mercado internacional no período em estudo. As causas desse resultado podem ser observadas na Figura 2.

A diminuição contínua da participação das exportações de Pernambuco nas exportações nacionais se deu por conta de uma estagnação das exportações locais, ao mesmo tempo em que as exportações brasileiras cresciam substancialmente, conforme a Figura 2 demonstra.

Assim, pode-se dizer que, de acordo com esse indicador, o setor açucareiro pernambucano obteve uma atuação bastante insatisfatória ao longo do período, no que se refere às exportações.

Outra avaliação da atividade do setor agroindustrial canavieiro ao longo dos últimos anos pode ser feita a partir do índice da produção mensal do setor, divulgada pelo IBGE. Nesse índice, além da produção de cana-deaçúcar, é considerada, também, a produção de açúcar, de álcool, de bebidas e de todos os demais produtos do referido setor. A Figura 3 apresenta a evolução do índice da produção mensal do setor no Estado de Pernambuco, durante a primeira metade da década de 90 .

Na Figura 3, nota-se, em primeiro lugar, que a produção oscila consideravelmente ao longo de cada ano. Como a grande maioria das atividades que estão ligadas à agricultura, a produção do setor agroindustrial canavieiro também tende a se concentrar, com maior intensidade, em determinados períodos de tempo específicos, mantendo uma certa tendência de altos e baixos ao longo do tempo. Esse caráter sazonal da produção agroindustrial reflete basicamente as diferentes condições climáticas que vigoram no decorrer de um período produtivo.

Pode-se observar ainda que, com relação à questão específica do desempenho do setor, se verifica que o mesmo atingiu o seu auge nos primeiros anos daquela série de dados, mais precisamente, por volta da safra 92/ 93. A produção sofreu uma ligeira queda a partir de então, estabilizando-se em um patamar inferior, o que pode ser visto através da observação dos picos atingidos pelo índice em análise, ao longo dos anos considerados. Pode-se observar que o desempenho do setor canavieiro deve ser considerado, no mínimo, como sendo insatisfatório, visto que, além de não apresentar qualquer crescimento, houve uma ligeira retração.

Para que se possa entender melhor o que deve ter acontecido no Estado de Pernambuco, convém que seja observado o comportamento do mesmo indicador para a produção brasileira como um todo, o que é feito através da Figura 4.

Observando a Figura 4, construída a partir de dados referentes ao Brasil como um todo, pode-se notar algumas diferenças bem visíveis em relação aos dados concernentes ao Estado de Pernambuco, apresentados na Figura 3.

Em primeiro lugar, ao contrário do Estado de Pernambuco, o setor agroindustrial canavieiro nacional apresenta uma tendência de expansão ao longo do período anali-

Figura 2: Exportações de açúcar - Pernambuco e Brasil (1987-95)

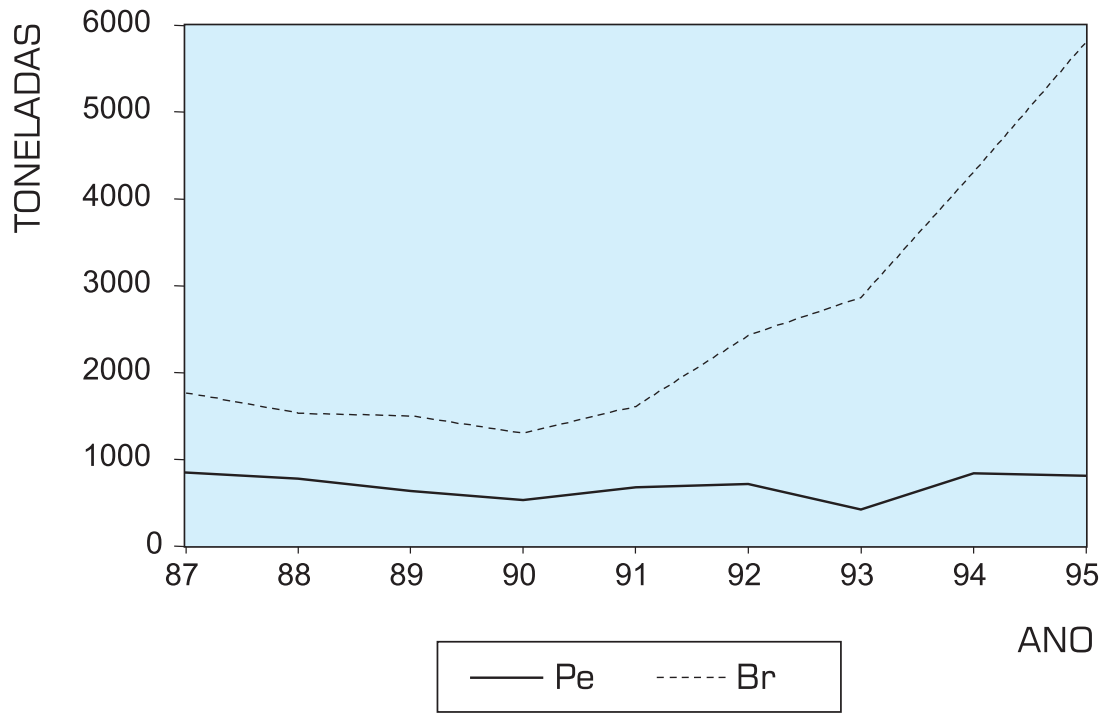

Fonte: Sindaçúcar e Banco Central 
sado, dado que os picos atingidos pela produção do setor se mostram cada vez mais elevados, embora aí sejam incluídas algumas contribuições negativas como a do próprio setor pernambucano. Assim, como Pernambuco tem uma certa representatividade nesse ramo, se fosse retirada a influência desse Estado para os dados que deram origem à Figura 4, acredita-se que o desempenho do setor brasileiro se mostraria bem mais satisfatório.

Figura 3: Índice da produção mensal do setor canavieiro (1991-95).

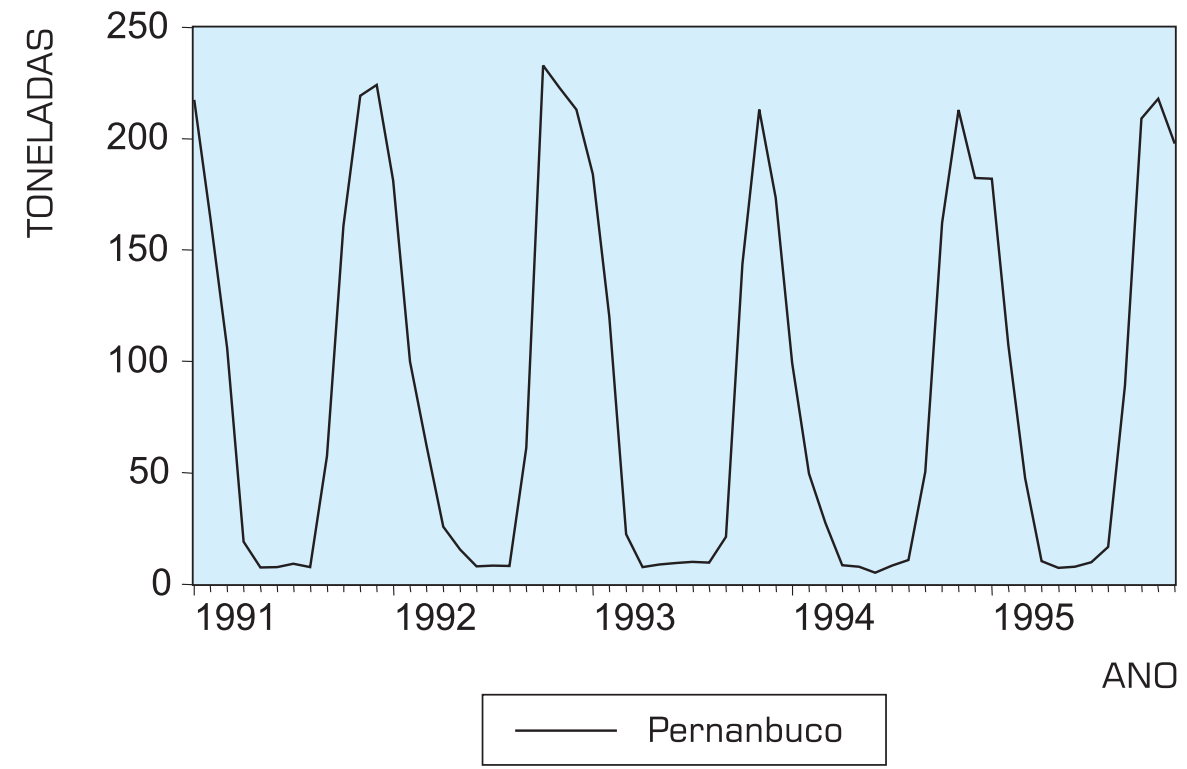

Fonte: IBGE. Base: Média de 1991 = 100. Calculados a partir de valores monetários da produção.

Figura 4: Índice da produção mensal do setor canavieiro (1991-95).

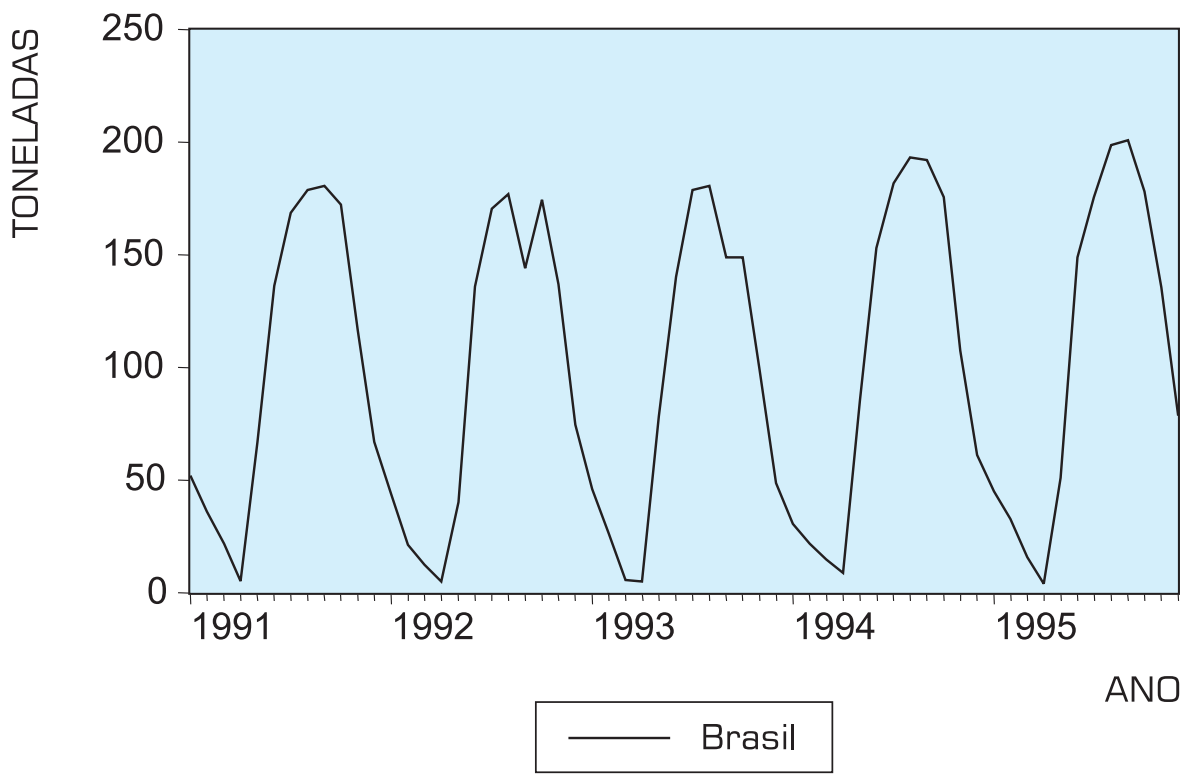

Fonte: IBGE. Base: Média de 1991 = 100. Calculados a partir de valores monetários da produção. 
Em segundo lugar, nota-se, também, que o ciclo de produção é mais longo para o Brasil (Figura 4) do que para o Estado de Pernambuco individualmente (Figura 3). Isso pode ser percebido pelo fato de as elevações da fig. 4 possuírem uma espessura mais larga do que aquelas constantes da Figura 3. A explicação está no fato de que os dados referentes ao Brasil são provenientes de Estados com diferentes períodos de colheita, como é o caso de Pernambuco e São Paulo, por exemplo, onde as condições climáticas são bem diferentes.

Por fim, vê-se claramente que o índice aqui tratado oscila numa faixa bem mais estreita na Figura 4 do que propriamente na Figura 3. Isso pode ser considerado como um indicativo de que a produção agroindustrial canavieira mostra-se bem mais instável no Estado de Pernambuco do que no Brasil como um todo. Um demonstrativo adicional dessa proposição pode ser dado a partir do cálculo da dispersão do índice apresentado para as duas regiões consideradas. No caso brasileiro, o desvio padrão do índice atinge o valor de 67,7 enquanto que, no caso pernambucano, o valor calculado é de 84,3 . Isto é, os dados são, realmente, mais dispersos no setor canavieiro de Pernambuco.

rumos que o setor vem tomando, ou seja, decadência, estagnação ou expansão.

Dessa forma, a partir de uma primeira constatação de que o setor agroindustrial canavieiro pernambucano obteve um desempenho insatisfatório na primeira metade da década de 90, deve-se fazer uma avaliação individual de alguns dos principais produtos que compõem a produção total do referido setor agroindustrial. Portanto, antes da aplicação dos índices de desempenho escolhidos para o ramo de atividade em questão, será feita a avaliação de alguns produtos, para que se possa obter uma visão panorâmica da situação.

Outro indicador importante de desempenho no mercado é a relação entre a quantidade exportada e a quantidade produzida. Quando um setor se caracteriza pela grande parcela de suas vendas destinada ao mercado internacional, ao mesmo pode ser atribuído um bom desempenho, dado que a concorrência nesse mercado é muito grande. No mercado internacional, além das empresas locais, estão também as empresas de todos os países do mundo. Acredita-se que conseguir vender uma parcela cada vez maior da produção em um mercado com essas características é sinal de bom desempenho.

O comportamento da

\section{- m Pernambuco, a agroindústria canavieira responde por uma parcela de, aproximadamente, 4\% do produto total da economia do Estado.} relação em análise, encontra-se na Figura 5. Quando comparados o início e o fim do período analisado, pode-se dizer que a participação das vendas externas no total produzido manteve-se

Em síntese, de acordo com o que foi visto acima, podese concluir que o setor agroindustrial canavieiro de Pernambuco não apresentou um desempenho suficiente ao longo da primeira metade da década de 90 . Quando visto isoladamente, nota-se que, além de não se expandir, sofre uma ligeira retração ao longo do período analisado, estabilizando os níveis de produção numa faixa inferior àquela apresentada nos primeiros anos. Quando comparado com o desempenho brasileiro do mesmo setor, os números se mostram ainda mais preocupantes, dado que, no âmbito nacional, o setor se expandiu e sofreu menores oscilações em seus níveis de produção.

Acredita-se que não se pode avaliar o desempenho de um setor observando apenas os indicadores acima analisados. Como visto anteriormente, a atuação competitiva de um setor deve ser medida por uma série de indicadores, que devem ser escolhidos de acordo com as suas características. No entanto, a trajetória dos índices acima analisados se constitui um indicativo relevante da performance do setor, pois tais índices podem revelar os praticamente constante. Comparando-se os valores obtidos para os anos de 1986 e 1995, vê-se que os mesmos são exatamente iguais, mais precisamente 0,60 . Visto dessa forma, tal fato talvez pudesse indicar que o desempenho do setor, pelo menos, não poderia ser considerado como insatisfatório, já que se trata de uma relação. Entretanto, observando melhor a Figura 5, vê-se que, dentro do intervalo citado, tal relação ficou, na maioria das vezes, abaixo de 0,60, por exemplo, chegando a 0,43 em 1990 . Pode-se perceber também que houve sempre grandes oscilações dentro do mesmo intervalo.

Observando o comportamento da relação entre exportações e quantidade produzida, retratada na Figura 5 e analisada acima, pode-se concluir que, por esse indicador não houve um desempenho satisfatório do setor açucareiro pernambucano ao longo do período de tempo em análise.

A evolução do preço obtido pelo produto também se torna uma variável importante na medida em que a mesma pode servir de estímulo ou desestímulo ao produtor. 
Um preço mais elevado tende a aumentar a lucratividade do setor na medida em que proporciona uma maior receita por unidade produzida. O contrário ocorre quando o preço sofre uma redução. Essa variável funciona muito mais como um indicativo de estímulos ao produtor do que simplesmente como uma medida de desempenho. Mesmo assim, por assumir tal importância, a mesma não deve deixar de fazer parte de uma análise dessa natureza. O comportamento dessa variável, para o caso do açúcar, no mercado internacional, ao longo do período analisado, é apresentado graficamente na Figura 6.

Observa-se na Figura 6, que há uma tendência de redução do preço obtido por tonelada, ao longo de todo o período analisado. Com exceção de uma substancial elevação entre 1988 e 1989, o preço pago por tonelada se mostrou sempre declinante.

A tendência assumida pelo preço do açúcar no mercado internacional pode indicar que o desempenho insatisfatório do setor, no período analisado, pode ter entre as suas causas problemas relacionados com preços, pelo menos no que se refere ao mercado do açúcar.

Torna-se conveniente verificar também o comportamento dos preços do produto no mercado interno. Como foi visto anteriormente, apenas uma parcela do açúcar é vendida no exterior, sendo o restante vendido no merca- do brasileiro. Por isso, o comportamento do preço no mercado local também se torna uma variável importante a ser analisada.

A Figura 7 apresenta o comportamento do preço do açúcar no mercado interno para o período compreendido entre 1987 e 1995.

Analisando essa figura, observa-se que o preço em vigor no mercado interno se comportou de maneira ainda mais negativa para o setor do que propriamente o preço no mercado externo. No caso do preço local, a tendência de redução foi muito mais intensa, caindo ao longo de todo o período de forma quase que contínua. Assim, pelos números apresentados para o preço do açúcar, não há qualquer evidência de que o setor agroindustrial canavieiro pudesse ter tirado algum proveito exclusivo dessa variável como forma de obter uma performance mais satisfatória. Pela queda do preço, tanto no mercado interno como no mercado externo, não é surpresa que a relação exportação/produção tenha se mantido constante ao longo do período.

No entanto, dado que outros produtos também contribuem significativamente para a produção total desse setor, convém verificar o comportamento dos preços no que se refere a tais produtos.

Um dos produtos de maior interesse nesse trabalho,

Figura 5: Relação exportação/produção de açúcar (1986-96).

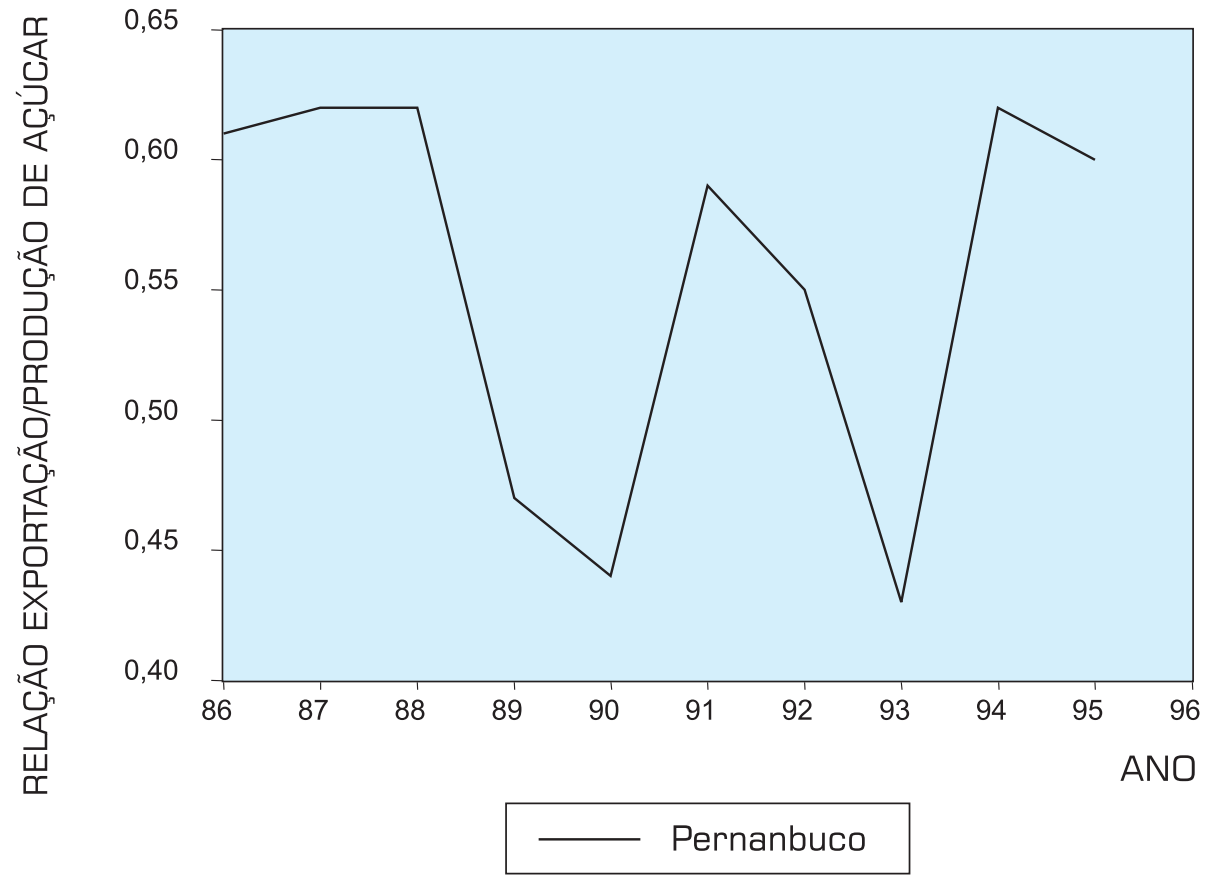

Fonte: Sindaçúcar. 
dada a sua importância para o setor canavieiro, é o álcool, que contribui com uma grande parcela das receitas dos produtores. Desse modo, o comportamento do preço do álcool no mercado interno é um indicador importante para o desempenho do referido setor. Na Figura 8, apresenta-se a evolução do preço desse produto no período em análise.

Figura 6: Preço do açúcar no mercado externo (1986-95).

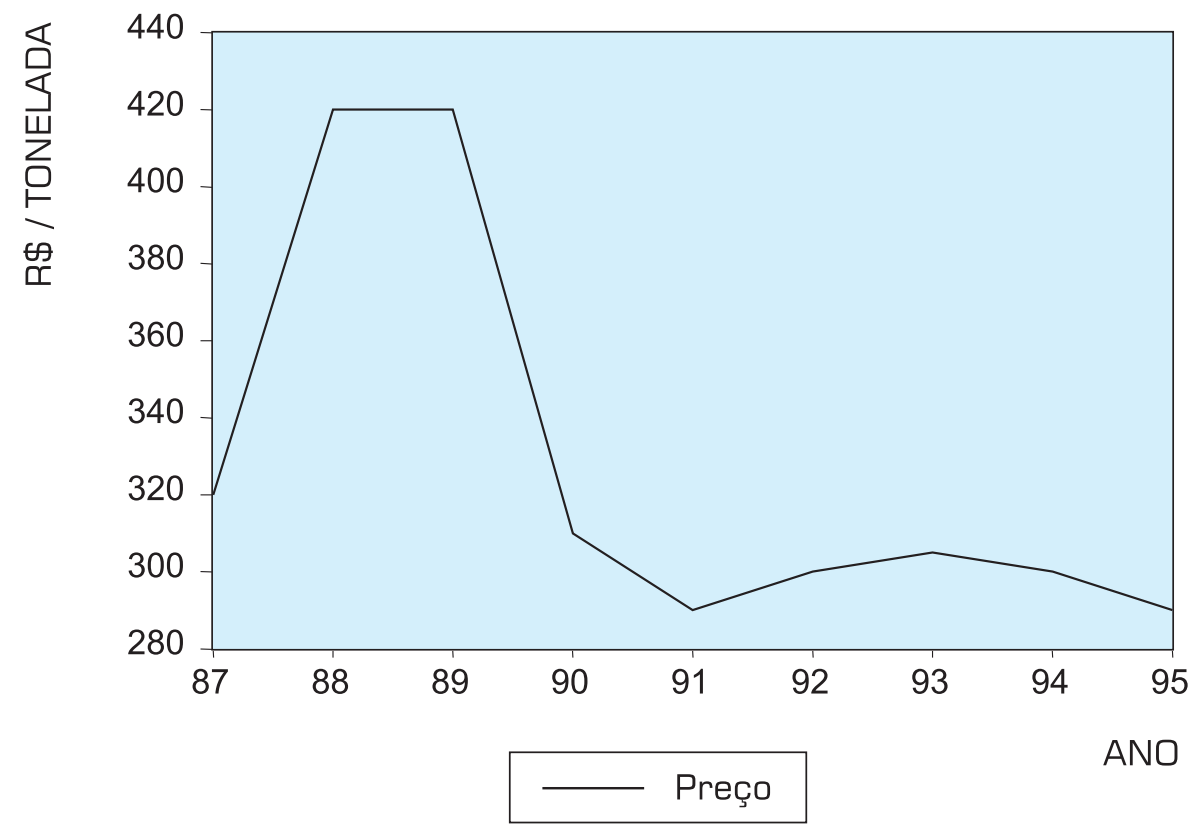

Fonte: Barros (1996). Base: em R\$ de abril de 1995 por tonelada.

Figura 7: Preço do açúcar no mercado interno (Nordeste, 1987-95).

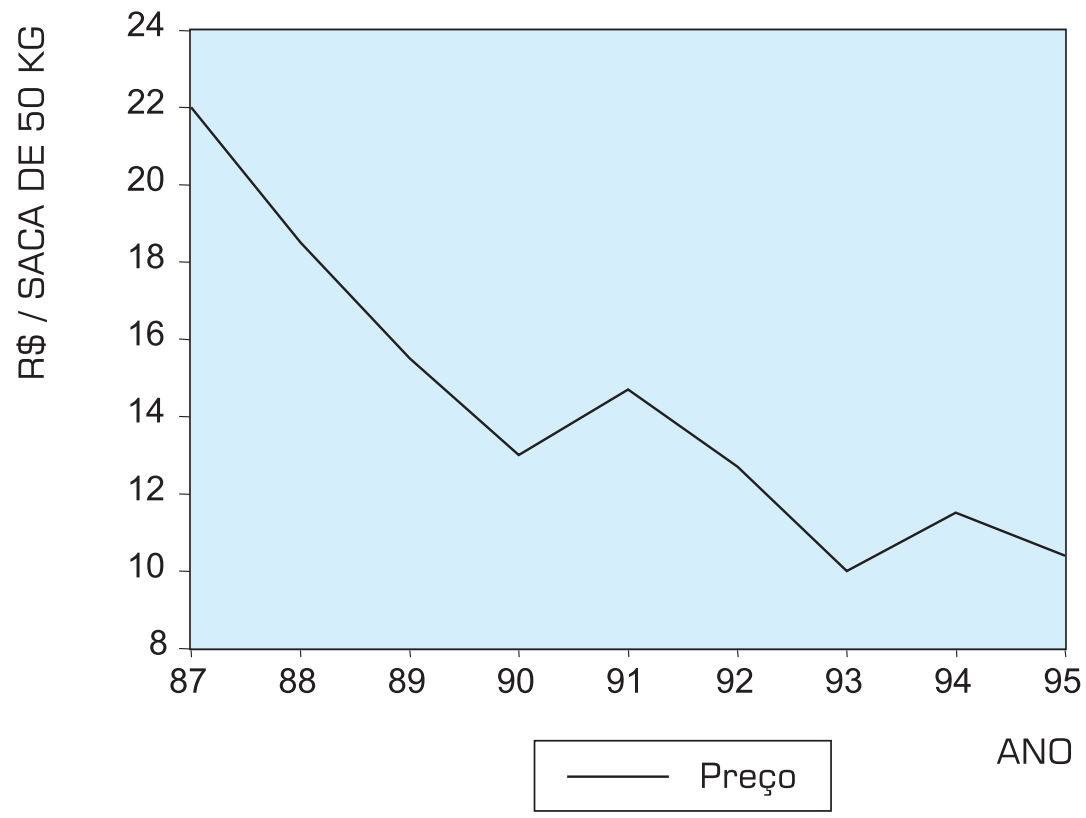

Fonte: Barros (1996). Base: em R\$ de abril de 1995 por saca de $50 \mathrm{~kg}$. 
Da mesma forma que o preço do açúcar, o preço do álcool caiu significativamente ao longo do período, mostrando que, também no caso desse produto, os incentivos provenientes dos preços não foram, de maneira alguma, positivos.

Uma vez analisados os indicadores de desempenho apresentados e os resultados obtidos, observa-se que os mesmos, de uma forma geral, indicam uma situação em que a performance do setor açucareiro pernambucano é crítica. A taxa de crescimento das vendas externas não se comportou satisfatoriamente, a relação exportações/produção apresentou grandes oscilações, enquanto que a participação das exportações pernambucanas nas exportações brasileiras reduziu-se significativamente ao longo dos anos. O comportamento dos preços, verificados em termos de mercado interno e mercado externo, mostrouse um fator extremamente negativo para a evolução do setor, dado que caíram intensamente ao longo dos anos.
Diante desse cenário, não havendo um só indicador com comportamento favorável, a conclusão a que se pode chegar é que o setor açucareiro pernambucano, realmente, não obteve um desempenho satisfatório de mercado, durante o período considerado.

\section{Indicadores de Eficiência do Setor Canavieiro}

Dando seqüência à análise dos indicadores, a performance do setor canavieiro será avaliada também pelos indicadores de eficiência, onde serão analisados alguns aspectos ligados aos custos de produção, como a produtividade da terra e o custo da mão-de-obra.

Os dados apresentados na Figura 9 representam uma média ponderada dos rendimentos obtidos pelas diversas faixas salariais apresentadas pelo IBGE. Cada faixa foi ponderada de acordo com o número de pessoas na classe, no total do número de indivíduos em atividade.

Figura 8: Preço do álcool no mercado interno (Nordeste, 1987-95).

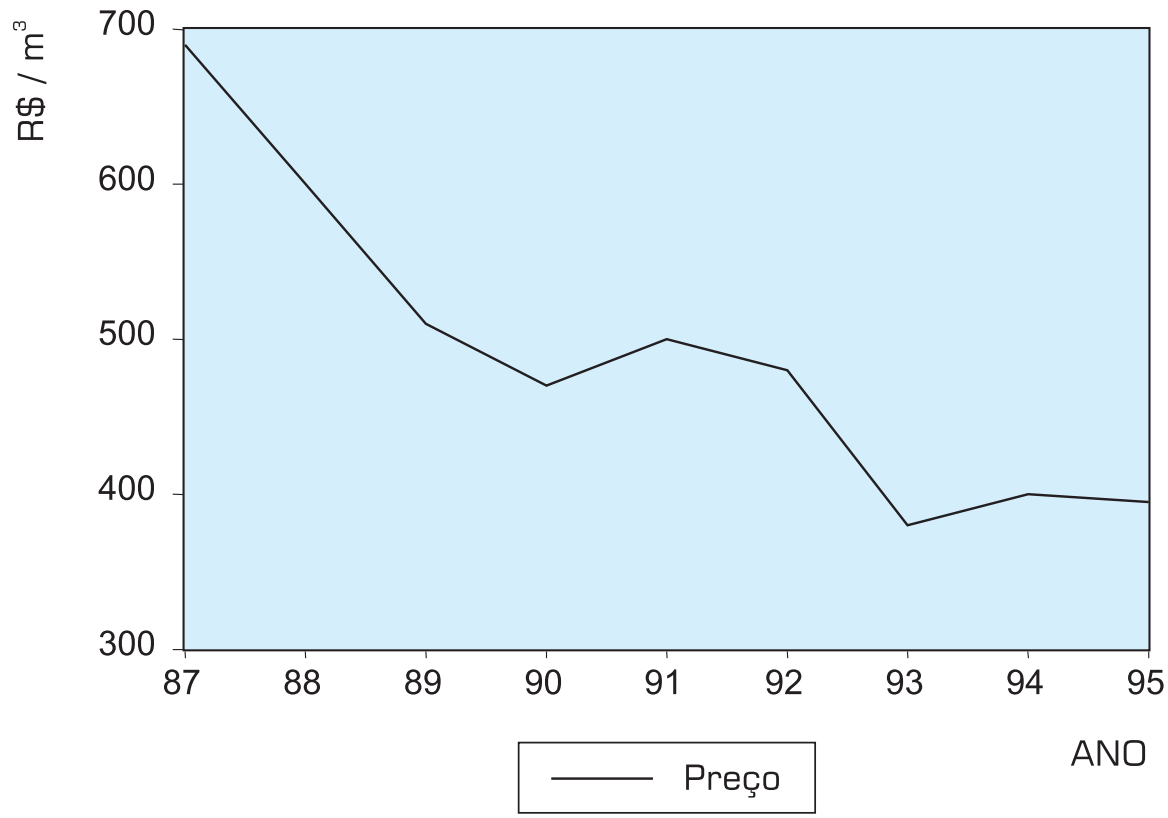

Fonte: Barros (1996). Base: em R\$ de abril de 1995 por $\mathrm{m}^{3}$.

Figura 9: Custo da mão-de-obra em Pernambuco (1987-96) a partir de dados do IBGE (em salários mínimos).

\begin{tabular}{|c|c|c|}
\hline ANOS & AGRÍCOLA & INDÚSTRIA DE TRANSFORMAÇÃO \\
\hline 1987 & 1,04 & 2,15 \\
\hline 1990 & 1,08 & 2,38 \\
\hline 1993 & 0,45 & 1,73 \\
\hline 1996 & 0,73 & 2,22 \\
\hline
\end{tabular}


Como é possível observar na Figura 9, o custo da mãode-obra em Pernambuco, no período analisado, de uma maneira geral, pode ser considerado como muito baixo, não representando nenhum obstáculo ao desempenho do setor. O salário médio na indústria de transformação não chega a 2,5 salários mínimos, enquanto no setor agrícola, nos períodos de maior remuneração, não passa de um salário mínimo. Considerando o baixo custo da mão-deobra, um setor como o agroindustrial canavieiro, onde está contabilizada grande parte da remuneração da mãode-obra agrícola, não pode atribuir ao pagamento de salários elevados a responsabilidade por qualquer desempenho insatisfatório que possa vir a obter. Como se observa, houve uma tendência de queda nos salários, o que poderia tornar o setor mais competitivo.

No entanto, pode ser que o setor careça de mão-deobra especializada, e este poderia vir a ser um fator importante para levar a um desempenho insatisfatório. Entretanto, a remuneração dos trabalhadores não deve ser apontada como causa de uma má performance. Dessa forma, torna-se conveniente verificar até que ponto a mão-de-obra local está devidamente qualificada, fator indispensável para a obtenção de um desempenho satisfatório em qualquer atividade.

Os indicadores de eficiência mostraram que a produtividade da terra em Pernambuco é muito mais baixa que nas demais regiões do País e, ao contrário do que ocorreu no restante do Brasil, a mesma declinou ao longo dos anos no Estado, como pode ser visto na Figura 10.

Para a baixa produtividade, a razão pode ser a utilização de terras pouco apropriadas ou de técnicas ultrapassadas, o que deve acabar resultando em uma baixa remuneração do trabalhador. Acredita-se que esses resultados devam ter contribuído diretamente para o desempenho competitivo insatisfatório do setor.

\section{Indicadores de Capacitação do Setor Canavieiro}

O conjunto dos indicadores de capacitação procura demonstrar o nível de preocupação com melhorias, tanto do pessoal envolvido como dos equipamentos e do próprio ambiente. Leva-se em consideração algumas medidas que se referem mais diretamente a especificidades tais como adoção de normas de qualidade, escolaridade e treinamento da mão-de-obra, gastos com pesquisa e desenvolvimento, gastos com melhorias ambientais, etc.

Para avaliar a situação em termos de instrução da força de trabalho à disposição do setor canavieiro pernambucano, a Figura 11 apresenta a média em termos de anos de estudo para a população economicamente ativa do Estado, em anos selecionados, de acordo com a sua localização, rural e urbana.

Nessa Figura 11, é apresentada a média ponderada dos anos de estudo, de acordo com a distribuição apresentada pelo IBGE. Cada faixa foi ponderada de acordo com o número de pessoas em cada uma no número total de indivíduos que compõem a população economicamente ativa do Estado.

Os dados da fig. 11 mostram que a população economicamente ativa do Estado de Pernambuco, ao longo do período analisado, possui um nível de instrução que deixa muito a desejar. A situação mais grave, como já era de se esperar, está no meio rural, onde os valores obtidos indicam que a média não chega a três anos de estudo, mostrando que esses indivíduos não possuem sequer o grau primário de educação. Além do mais, ao longo do tempo, pode-se notar que a mesma variável não mostra

Figura 10: Produtividade da terra no cultivo da cana-de-açúcar (1987-96) a partir de dados do IBGE.

\begin{tabular}{|c|c|c|c|}
\hline ANOS & PERNAMBUCO (T/H ${ }_{\mathbf{A}}$ ) & SÃO PAULO (T/H ${ }_{\mathbf{A}}$ ) & BRASIL (T/H ${ }_{\mathbf{A}}$ \\
\hline 1987 & 52,83 & 75,52 & 62,29 \\
\hline 1988 & 50,64 & 75,84 & 61,99 \\
\hline 1989 & 54,14 & 73,96 & 61,48 \\
\hline 1990 & 48,83 & 76,07 & 61,96 \\
\hline 1991 & 50,32 & 73,53 & 64,60 \\
\hline 1992 & 51,65 & 77,00 & 63,29 \\
\hline 1993 & 39,49 & 78,41 & 67,23 \\
\hline 1994 & 48,16 & 80,11 & 66,61 \\
\hline 1995 & 49,46 & 76,45 & 67,25 \\
\hline
\end{tabular}


qualquer perspectiva de elevação nos níveis dos seus valores. No meio urbano, embora o nível de instrução ainda seja baixo, nota-se que há uma perspectiva de mudança no sentido positivo ao longo do tempo.

Acredita-se que uma das explicações para os baixos valores encontrados é o alto índice de analfabetismo da população economicamente ativa do Estado de Pernambuco. Segundo dados do IBGE, essa taxa se encontrava em torno de $30 \%$ em 1994. Ao incluir essa parcela da mão-de-obra nos cálculos anteriores, é normal que os valores encontrados para a variável em questão sejam baixos, conforme os dados da Figura 11.

De acordo com a situação analisada acima, pode-se dizer que o setor agroindustrial canavieiro pernambucano tem, a sua disposição, uma mão-de-obra muito pouco qualificada, representando um empecilho ao melhor desempenho do referido setor, conforme justificativas anteriormente apresentadas.

Em relação ao outro indicador de capacitação estudado - gastos com pesquisa e desenvolvimento - segundo dados apresentados por Barros (1996), não há qualquer tipo preocupação nesse sentido por parte dos produtores do setor canavieiro pernambucano, visto que não há gastos desse tipo por parte dos empresários do setor canavieiro de Pernambuco. Segundo o referido autor, isso se deve, basicamente, ao fato de os retornos dos investimentos em pesquisas não poderem ser internalizados pelos que tentam implementá-los. Isto é, como os resultados podem ser facilmente copiados pelos demais produtores, nenhum deles, individualmente, se disporia a bancar os gastos com esse tipo de investimento.

Posto que o governo também não desenvolveu qualquer programa significativo de pesquisa direcionada ao setor em análise, no Estado de Pernambuco, o resultado é a ausência de pesquisas no setor canavieiro local no período estudado. Isso acarreta sérios prejuízos ao setor em questão, já que se trata de um dos mais viáveis meios de aumentar a produtividade ao longo do tempo. Assim, a exemplo de outros indicadores, esse também tende a contribuir para um desempenho insatisfatório do setor canavieiro pernambucano.

\section{CONCLUSÕES}

Sabe-se que o setor agroindustrial canavieiro tem uma importância para o Estado de Pernambuco que remonta ao período colonial da história brasileira. Após a extração do pau-brasil, a primeira atividade realmente viável que os portugueses exploraram no Brasil foi a atividade canavieira, localizada principalmente na região que atualmente representa parte do Estado de Pernambuco.

Figura 11: Nível de instrução da mão-de-obra em Pernambuco (1987-96) a partir de dados do IBGE (em anos de estudo)

\begin{tabular}{|c|c|c|}
\hline ANOS & RURAL & URBANA \\
\hline 1987 & 2,70 & 5,00 \\
\hline 1990 & 2,32 & 5,32 \\
\hline 1993 & 2,28 & 5,83 \\
\hline 1996 & 2,54 & 6,33 \\
\hline
\end{tabular}


beu um grande estímulo, resultante da entrada em vigor do Programa Nacional do Álcool. Dadas as vantagens desse programa, como era esperado, o setor canavieiro pernambucano experimentou grande prosperidade no referido período. Com juros e preços altamente favoráveis, a produção local dos principais produtos do setor cresceu significativamente, destacando-se a produção específica do álcool, reflexo das próprias finalidades do programa.

Passado esse período, com a retirada dos incentivos concedidos pelo Proálcool, começa uma fase em que o setor fica bem mais exposto às condições de mercado e, em decorrência disso ou não, a agroindústria canavieira pernambucana entra em um período de grandes dificuldades. Em virtude das as diversas especulações no meio acadêmico e nos próprios meios de comunicação local, a importância de tais dificuldades, bem como as suas verdadeiras causas, tornou-se um assunto bastante debatido.

\section{\& preciso também manter programas de - treinamento constante, ou seja, uma força de trabalho caraterizada pela multifuncionalidade.}

Isso ficou bastante claro através da comparação da evolução dos indicadores de produtividade e participação no total das exportações. Ou seja, a falta de um programa maior de incentivos ao setor canavieiro prejudica igualmente a todos, não justificando, assim, a perda de competitividade somente dos produtores pernambucanos em relação a outros Estados da federação, como por exemplo São Paulo.

O que justifica a perda de competitividade em relação a outros Estados, pode ser algo ligado a questões como níveis de capacitação e eficiência, isto é, algo ligado ao próprio modo como a produção local se desenvolve. Nesse sentido, os resultados obtidos para alguns dos indicadores aplicados podem dar uma noção global das verdadeiras causas dos problemas encontrados.

Fatores como relevo inadequado e instabilidades climáticas não podem mais justificar a totalidade dos problemas do setor. Da mesma forma, não se pode utilizar a justificativa da queda dos preços no mercado. Em um ambiente em que os produtores não se dispõem a gastar nenhum recurso com o desenvolvimento de novos métodos de plantio, técnicas de produção mais modernas, descoberta de novas variedades

Uma forma apropriada para análise da importância e das causas das dificuldades enfrentadas pelo setor canavieiro é através do estudo do desempenho competitivo do referido setor, a partir do emprego de um conjunto de indicadores, para os quais foram escolhidos três tipos: desempenho no mercado, eficiência e capacitação. A situação encontrada confirmou que o desempenho competitivo do setor agroindustrial canavieiro de Pernambuco sofreu uma deterioração nos anos que se seguiram ao enfraquecimento e extinção do Proálcool, dentro de um ambiente de maior exposição ao mercado.

Com relação às variáveis analisadas, tanto os indicadores de eficiência como os de capacitação e aqueles de desempenho no mercado apresentaram-se igualmente insatisfatórios. Isso, de certa forma, mostra que as causas do desempenho insatisfatório do setor são bastante generalizadas. A produtividade baixa e decrescente, o baixo nível de instrução da força de trabalho, a falta de investimento em pesquisa e desenvolvimento, entre outros, são fatores que certamente contribuíram para a performance insatisfatória encontrada.

Pode ser que o setor apresentasse outra situação, caso tivessem sido mantidos os incentivos do Proálcool. No entanto, com a extinção desse programa, o que é importante analisar é que o setor canavieiro pernambucano perdeu posição em relação às demais regiões brasileiras. mais adequadas, treinamento da mão-de-obra, entre outros, torna-se pouco provável qualquer expansão. Compromete-se, desse modo, a produtividade do setor, que é fator fundamental para a sobrevivência em um ambiente de maior exposição ao mercado, principalmente no caso em que o mercado internacional é muito importante.

Diante desse quadro, não é surpresa o fato de que o setor canavieiro pernambucano tenha passado por inúmeras dificuldades ao longo do período em análise. Deterioração dos níveis de produção, fechamento de usinas, endividamento e perda de mercado, foram características marcantes do comportamento do referido setor. De acordo com os indicadores analisados, a situação é realmente preocupante, visto que o desempenho do setor agroindustrial canavieiro no Estado de Pernambuco foi realmente insatisfatório ao longo do período considerado.

A sobrevivência desse importante setor de produção do Estado de Pernambuco requer, assim, uma mudança de atitude por parte dos produtores locais. Isso pode começar pela união dos mesmos em torno de cooperativas que viabilizem a realização de pesquisas, que contribuam para a adoção de métodos e técnicas de produção mais apropriadas, variedades mais adequadas às condições da região, como também um melhor aproveitamento dos subprodutos gerados pelo setor, como já ocorre em outros Estados. 
Acredita-se que o setor canavieiro pernambucano poderia até se beneficiar de uma atitude governamental no sentido de financiar a realização das pesquisas necessárias. No entanto, em virtude das condições financeiras do Estado, nos seus três níveis de governo, esta não seria uma estratégia viável, pelo menos a curto prazo. A permanecer a situação atual, a tendência é que as disparidades entre Estados como Pernambuco e São Paulo se ampliem cada vez mais, tornando o setor canavieiro pernambucano cada vez menos competitivo.

Deve-se ressaltar também que, dado um ambiente mais competitivo e técnicas e equipamentos de produção mais complexos, é cada vez maior a necessidade de se dispor de mão-de-obra mais qualificada. Além de um nível de instrução cada vez mais elevado, é preciso também manter programas de treinamento constante, uma vez que os novos métodos requerem uma força de trabalho caraterizada pela multifuncionalidade.

Desse modo, deve-se procurar melhorar as tecnologias e os processos. Nos mercados em constante processo de mudança, não é possível continuar utilizando, no presente, métodos e técnicas do passado. A sobrevivên- cia do setor requer a utilização do que há de mais moderno em termos de tecnologia, ao lado de uma força de trabalho preparada para lidar com a mesma.

É comum encontrar-se, entre as soluções apontadas para o problema, a reivindicação de uma participação mais intensa por parte dos governos, através da adoção de medidas tais como as que vigoraram com o Programa Nacional do Álcool, ou através da fixação de preços mais elevados para os produtos do setor. A presença do governo reduz as incertezas e pode contribuir para um melhor desempenho. No entanto, a mesma não pode durar para sempre e os produtores têm que se preparar para sobreviver sob condições de maior exposição ao mercado.

Portanto, tudo indica que a solução dos problemas do setor não depende de uma atitude dos governos, mas sim de uma atitude das próprias empresas, já que a base da competitividade encontra-se na empresa, e não fora dela. Acredita-se que somente com medidas efetivas, como investimento em pesquisa e desenvolvimento, é que o setor canavieiro pernambucano pode alcançar os níveis de competitividade necessários à sua continuidade.

\section{Artigo recebido em 21/01/2003 Aprovado para publicação em 05/03/2004}

\section{- Bibliografia}

ANDRADE, Bonifácio. (1975) Evolução da agroindústria do açúcar em Pernambuco. Revista Econômica do Nordeste. Fortaleza, v. 2, n. 2. p. 15966 , jul./dez.

ANDRADE, Manuel C. (1988) Área do Sistema Canavieiro. Recife: SUDENE.

(1989) História das Usinas de Açúcar de Pernambuco. Recife: Massangana.

BANCO CENTRAL. Boletim do Banco Central do Brasil. Brasília, vários números.

BARRoS, Alexandre R. (1996) Uma avaliação das políticas para o setor sucroalcooleiro no Brasil: o que a nova evidência mostra. Revista Econômica do Nordeste. Fortaleza, v. 27, n. 3, p. 322-362, jul./set..

(1996) O setor sucroalcooleiro de Pernambuco. Pernambuco Conjuntural. Recife, v. 1, n. 1, p. 1-19, jan./mar.
BONELLI, Regis, FLEURY, Paulo. F.; FRITSCH, Winston. (1994) Indicadores microeconômicos do desempenho competitivo. Revista de Administração. São Paulo. v. 29, n. 2, p. 3-19, abr./jun.

CAFÉ, Sônia L.; SILVA, Ricardo; ALLEN, David J. (1995) Indicadores de competitividade para o BNDES. Revista do BNDES. Rio de Janeiro, v. 2 ,n. 3, p. $69-88$, jun.

CARVAlHO, Maria A. (1998) Políticas públicas e competitividade da agricultura. Anais do XXVI Encontro Nacional de Economia. Vitória, v. 3, p.1511-1530.

CNI. (1991) Competitividade Industrial: uma estratégia para o Brasil. Rio de Janeiro.

COUTINHO, Luciano; FERRAZ, João C. (1995) Estudo da Competitividade da Indústria Brasileira. 3. ed. Campinas: Papirus.
FERRAZ, João C.; KUPFER, David; HAGUENAUER, Lia. (1997) Made in Brasil: desafios competitivos para a indústria. Rio de Janeiro: Campos

FURTADO, Celso. (1998) Formação Econômica do Brasil. 27ed. São Paulo: Compania Editora Nacional.

IBGE. Anuário Estatístico do Brasil. Rio de Janeiro.

JALFRIM, André de A. (1997) $A$ indústria Sucroalcooleira Pernambucana: uma análise qualitativa. Recife. (Monografia de graduação - Universidade Federal de Pernambuco).

LIMA, João P. (1997) O estado e a agroindústria canavieira no Nordeste: a acumulação administrada. Revista Econômica do Nordeste. Fortaleza, v. 19 , n. 4 , p. 431-449, out./dez.
LIMA \& SILVA, Gerson V. (1995) A economia canavieira de Pernambuco e a restruturação necessária. Revista Econômica do Nordeste. Fortaleza, v 26, n. 2, p. 181-203, abr./jun.

LOPES, Luís. A. (1996) Vinte Anos de Proálcool: Avaliação e perspectivas. Economia \& Empresa. São Paulo, v. 3 , n. 2, p. 49-57, abr./jun.

MAGALHÃES, João P. A. (1991) Proálcool: uma avaliação global. Rio de Janeiro: Astel.

SEBRAE. (1998) Qualidade $e$ Produtividade na Indústria Brasileira. Mimeo.

SHIKIDA, P. F. (1996) Modernização da agroindústria canavieira durante o Proálcool: uma abordagem exploratória através da análise fatorial. Economia \& Empresa. São Paulo, v. 3, n.1, p. 20 33, jan./mar

SINDAÇÚCAR. (1997) Datafile Sindaçúcar. Recife. 